Journal of Medical Education Development, 2018, Vol 11, No 30, 1 - 3

http://zums.ac.ir/edujournal/

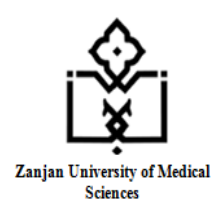

\title{
Medical Teaching and Learning: Growth Versus Fixed Mindset in Medical
}

\section{Education}

\author{
Vahid Khalkhali ${ }^{*}$ (D) \\ ${ }^{1}$ Department of Psychology, Islamic Azad University, Malayer Branch, Malayer, Iran.
}

Individuals develop beliefs and mindsets as a meaning system to create structures for their world, which in turn plays a key role in their motivations and behaviors, particularly in the teaching and learning contexts. Mindset could be examined within the frameworks of growth and fixed attitude. Dweck [1] has defined mindset as the perspective of individuals toward their innate attributes (e.g., abilities and personality traits) as fixed, uncontrollable characteristics (fixed mindset) that cannot change through effort or malleable, controllable qualities that could be promoted through effort and investment (growth mindset). In this regard, Dweck [2] argues that the fixed mindset creates an urgency to prove oneself, and the failures faced by the individual may be perceived as a direct measure of their competence and selfworth. These individuals are not only more likely to make negative judgments about their intelligence, but they are also more likely to show negative affection and debilitation following failures. On the other hand, individuals with the growth mindset are conscious and willing to voluntarily receive ego threats within their perception of their innate abilities, so that they may continually re-evaluate their learning process and maximize their potential. These mindsets lead students to recognize re-evaluation and feedback variably. Medical education is

"Corresponding author: Vahid Khalkhali, Email: v.khalkhali@iau-malayer.ac.ir

This article is referenced as follows: Khalkhali V. Medical Teaching and Learning: Growth versus Fixed Mindset. J Med Educ Dev. 2018; 11 (30):1-3 
largely dependent on continuous re-evaluation and feedback $[2,3]$.

Dweck's theory of mindset may have special relevance to medical education. The rigors of the process of selecting physicians may favor the fixed mindset over the growth mindset. Fear of poor performance in the presence of colleagues and patients when the stakes are high or in the case of lifethreatening conditions may support the mindset that seeks self-improvement and feedback [4]. Negative feedback is often a sign that students need to change their behaviors and adopt more effective strategies in the future. For those with a fixed mindset of intelligence, failure signifies the lack of ability. By attributing negative feedback to external factors, such students avoid behavioral changes, setting themselves up for repeated failures. With respect to adopting strategies for the future, students with the fixed mindset are inclined toward the negative strategies that allow them to avoid effort. By contrast, for those with the growth mindset, negative feedback is an indication that they have not tried hard enough. By attributing negative feedback to their lack of effort, these students could take control of the situation and have better performance in the future.

A specific approach for physicians to constantly re-evaluate their skills and intellect is to receive and review feedback from medical errors $[3,5]$. Throughout their training, physicians may receive threats to their perception of their innate abilities and clinical reasoning, especially when committing or admitting to medical errors.

Several studies have been focused on the rate of medical errors and their effect on patient safety [3]. The mindset theory could predict that physicians with various mindsets might respond differently to committing or admitting to medical errors. This variation in the mindset and reporting of medical errors could have educational implications for clinical practice, since the change in the mindset via targeted training could promote the feedback in medical education and enhance clinical practice. It is notable that to be a good teacher and learner, one needs to adopt the growth mindset. Teachers should avoid the belief that they have nothing further to learn and that it is the learners who are supposed to change in accordance with teaching.

\section{References}

1- Vali K. Task Difficulty, Self-Handicapping and Performance: A Study of Implicit Theories of Ability. International Online Journal of Educational Sciences. 2012, 4 (3), 592-601. 
2- Teunissen PW, Bok HGJ. Believing is seeing: how people's beliefs influence goals, emotions and behavior. Med Educ. 2013; 47: 1064-72.

3- Coffey M, Thomson K, Tallett S, Matlow A. Pediatric residents' decisionmaking around disclosing and reporting adverse events: the importance of social context. Acad Med. 2010; $85: 1619-25$.

4- Jegathesan, M, Vitberg, M and Pusic, V. A survey of mindset theories of intelligence and medical error self-reporting among pediatric housestaff and faculty. BMC Medical Education. 2016: 16:58: $2-6$

5- An PG, Rabatin JS, Manwell LB, et al. Burden of difficult encounters in primary care: data from the minimizing error, maximizing outcomes study. Arch Intern Med. 2009; 169(4):410-4. 